\title{
Thank you to our reviewers
}

The Editors of the Journal of Community Safety and Well-Being (CSWB) would like to publicly acknowledge and thank the peer reviewers listed below who have reviewed manuscripts for the Journal from December 1, 2020 to November 30, 2021. These experts volunteer their valuable time and expertise to provide thoughtful comments, recommendations, and insightful guidance to our authors. Without their efforts, the quality of the Journal could not be sustained. We express our appreciation and gratitude to all reviewers for their important contribution to the articles published in the Journal of CSWB.

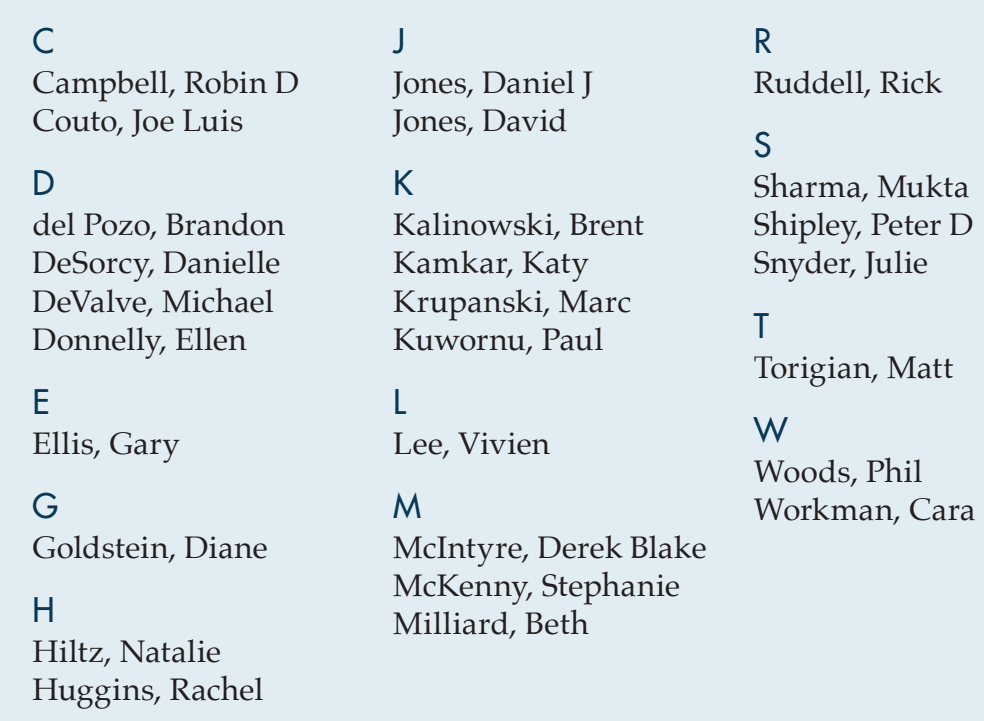

